Received: 12 October 2017

Accepted: 13 February 2018

Published online: 14 March 2018

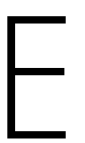

C
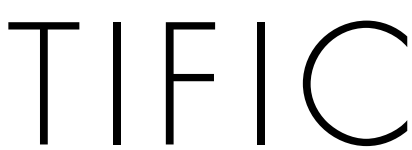

REP

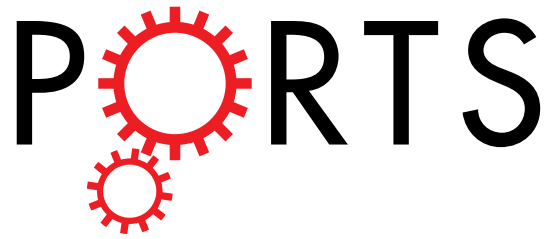

OPEN

\section{Influence of Polymer Substrate Damage on the Time Dependent Cracking of $\mathrm{SiN}_{\mathrm{x}}$ Barrier Films}

\author{
Kyungjin Kim, Hao Luo, Ting Zhu, Olivier N. Pierron \& Samuel Graham
}

This work is concerned with the long-term behavior of environmentally-assisted subcritical cracking of PECVD SiN $\mathrm{N}_{\mathrm{x}}$ barrier films on polyethylene terephthalate (PET) and polyimide (PI) substrates. While environmentally-assisted channel cracking in $\mathrm{SiN}_{\mathrm{x}}$ has been previously demonstrated, with constant crack growth rates over short periods of time $(<1$ hour) during which no substrate damage was observed, the present experiments over longer periods reveal a regime where cracking also develops in the polymer substrate. This time-dependent local cracking of the polymer underneath the channel crack is expected based on creep rupture or static fatigue. Our combined in-situ microscopy and finiteelement modeling results highlight the combined effects of neighboring cracks and substrate cracking on the crack growth rate evolution in the film. In most cases, the subcritical crack growth rates decrease over time by up to two orders of magnitude until steady-state rates are reached. For $\mathrm{SiN}_{\mathrm{x}}$ on $\mathrm{Pl}$, crack growth rates were found to be more stable over time due to the lack of crack growth in the substrate as compared to $\mathrm{SiN}_{\mathrm{x}}$ on PET. These results provide a guideline to effectively improving the long-term reliability of flexible barriers by a substrate possessing high strength which limits substrate damage.

The development of ultrabarriers has been motivated over the past decade by their need for organic electronics and thin film photovoltaic technologies. Currently, the technology for ultrabarrier films has reached an effective water vapor transmission rate less than $10^{-4} \mathrm{~g} \cdot \mathrm{m}^{-2} \mathrm{day}^{-11-7}$. With recent demonstrations of curved and now foldable organic displays, solar cells and light emitting diodes with radii of curvature down to $30 \mu \mathrm{m}^{8}$, the understanding of their reliability under mechanical deformation has become paramount to their adoption as a viable technology ${ }^{9-16}$. This is critically important for ultrabarrier films that are made with brittle inorganic thin films and have limited tolerance to strain. Channel cracking is a primary failure mode of concern for ultrabarrier films which has been studied for several barrier film architectures ${ }^{17-21}$. These studies mainly reported crack onset strain values, i.e. the strain at which visual cracks appear in the barrier during bending or stretching test. However, these values may not be sufficient to describe the reliability of brittle barrier films on polymer substrates under mechanical deformation since it does not capture time dependent deformation that can be induced during flexible deformation. This mode of failure can be important for applications such as bendable or foldable electronics that are held in their flexed state of strain for a period of time.

Recently, we reported the existence of time-dependent subcritical channel crack growth in PECVD SiN bar- $_{\mathrm{x}}$ rier films deposited on polyethylene terephthalate (PET) substrates, as illustrated in Fig. $1 \mathrm{a}^{22,23}$. More specifically, we showed that PECVD SiN ${ }_{\mathrm{x}}$ films undergo environmentally-assisted cracking and that water molecules are the chemically-active species influencing the crack growth process. As a result, channel crack growth velocity, $v$, is a strong function of environment and driving force for crack extension, $G$, as shown in Fig. $1 \mathrm{~b}$. The driving force $G$ in Fig. $1 \mathrm{~b}$ can be calculated accurately using the following equation ${ }^{24,25}$.

$$
G_{s s}=Z E_{f}^{*}\left(\varepsilon_{a p p}+\varepsilon_{r e s}\right)^{2} h_{f}
$$

where $\varepsilon_{a p p}$ and $\varepsilon_{\text {res }}$ are the applied and residual strains in the film; $E_{f}^{*}$ and $h_{f}$ are the plane strain elastic modulus and thickness of the film; and $Z$ is the dimensionless energy release rate, which depends on the elastic mismatch between film and substrate. The elastic mismatch was characterized by Dundurs' parameters $\alpha, \beta$ given by ${ }^{26}$

George W. Woodruff School of Mechanical Engineering, Georgia Institute of Technology, Atlanta, Georgia, 30332, United States. Correspondence and requests for materials should be addressed to O.N.P. (email: olivier.pierron@ me.gatech.edu) or S.G. (email: sgraham@gatech.edu) 
a
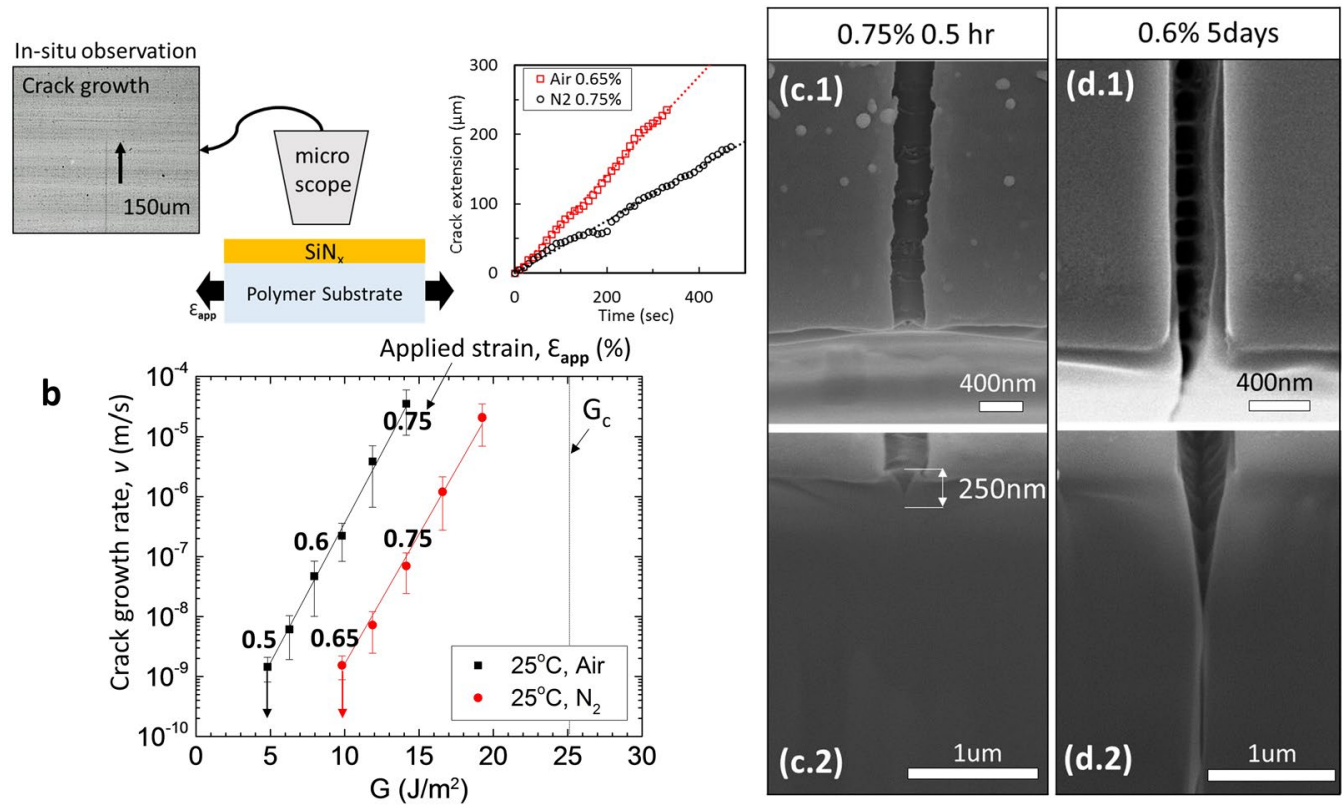

Figure 1. (a) Schematic illustration of in-situ microscopy of a $\mathrm{SiN}_{\mathrm{x}} / \mathrm{PET}$ sample kept at different applied strains, for optical imaging and measurement of channel crack growth and crack extension as a function of time. (b) Measured crack growth rate as a function of driving force $\mathrm{G}$ for a channel crack in a $250 \mathrm{~nm}$-thick $\mathrm{SiN}_{\mathrm{x}}$ film in air and nitrogen, respectively. (c,d) SEM images of $\mathrm{SiN}_{\mathrm{x}} / \mathrm{PET}$ cross section (cut by FIB) showing the channel crack in the film as well as the substrate crack beneath the channel crack, under (c.1-2) applied strain $0.75 \%$ for half an hour and (d.1-2) applied strain $0.6 \%$ for 5 days.

$$
\begin{gathered}
\alpha=\frac{E_{f}^{*}-E_{s}^{*}}{E_{f}^{*}-E_{s}^{*}} \\
\beta=\frac{1}{2} \frac{\mu_{f}\left(1-2 v_{s}\right)-\mu_{s}\left(1-2 v_{f}\right)}{\mu_{f}\left(1-v_{s}\right)+\mu_{s}\left(1-v_{f}\right)}
\end{gathered}
$$

where $E_{s}{ }^{*}$ is the plane-strain elastic modulus of the substrate, $\mu_{f}$ and $\mu_{s}$ are the shear modulus, $v_{f}$ and $v_{s}$ are Poisson's ratio of the film and substrate, respectively. Eq. (1) illustrates the fact that the driving force for channel crack extension is a strong function of the effective substrate constraint (through the coefficient $Z$ and therefore $\alpha$. The dependence on $\beta$ is weak.). As such, this equation is only accurate for channel cracking of an isolated crack (whose front width corresponds exactly to the film thickness). For this reason, the data shown in Fig. 1b were only collected for isolated cracks for which no substrate damage was observed (i.e. for periods of time less than 30 minutes).

Previous work has already quantified the effect of substrate cracking on the driving force for channel $\operatorname{cracks}^{27,28}$, interaction with neighboring cracks by crack spacing ${ }^{29,30}$ and their application as sensors ${ }^{31}$. However, the influence of substrate cracking on the long-term time-dependent subcritical cracking has not been studied. In this work, we further investigate the time-dependent environmentally assisted cracking in PECVD SiN barrier films by testing over extended periods of time (i.e. days versus minutes in contrast to our previous study) ${ }^{22}$. Our experimental and numerical results help elucidate the effects of substrate cracking on the driving force (and therefore velocity) of channel cracks in $\mathrm{PECVD} \mathrm{SiN}_{\mathrm{x}}$ barrier layers, which is key to predicting long term damage growth in barrier films under deformation. Specifically, our results highlight various scenarios of increasing, decreasing, or constant crack velocities depending on the substrate cracking configuration and distance to surrounding cracks (i.e. crack density). Details of the experiments and results are described in the following sections.

\section{Results and Discussion}

Crack Configuration. To test the cracking behavior under extended deformation, PET and PI samples coated with $250 \mathrm{~nm}$ of PECVD $\mathrm{SiN}_{\mathrm{x}}$ were tested under tensile deformation and held at fixed strains. Crack growth rates were measured by in-situ optical microscopy. Figure 1c and d show SEM images of focused ion beam (FIB) cross sections of $\mathrm{SiN}_{\mathrm{x}}$ on PET that were tested at an applied strain of $0.75 \%$ for $0.5 \mathrm{~h}$ and at $0.6 \%$ for 5 days, respectively. The critical onset strain for these films was found to be $0.95 \% \pm 0.2 \%$ and subcritical crack growth was observed for these specimens. The SEM images show no PET substrate cracking for the specimen held at $0.75 \%$ for $0.5 \mathrm{~h}$ (Fig. 1c.1-2). This is consistent with the analysis in our previous study which occurred in a regime without substrate cracking. This is also consistent with constant rates of crack growth in $\mathrm{SiN}_{\mathrm{x}}$ films measured during short times $(\sim 0.5 \mathrm{~h})$ after channel cracking was first observed. In contrast, as clearly shown in (Fig. 1d.1-2), FIB 

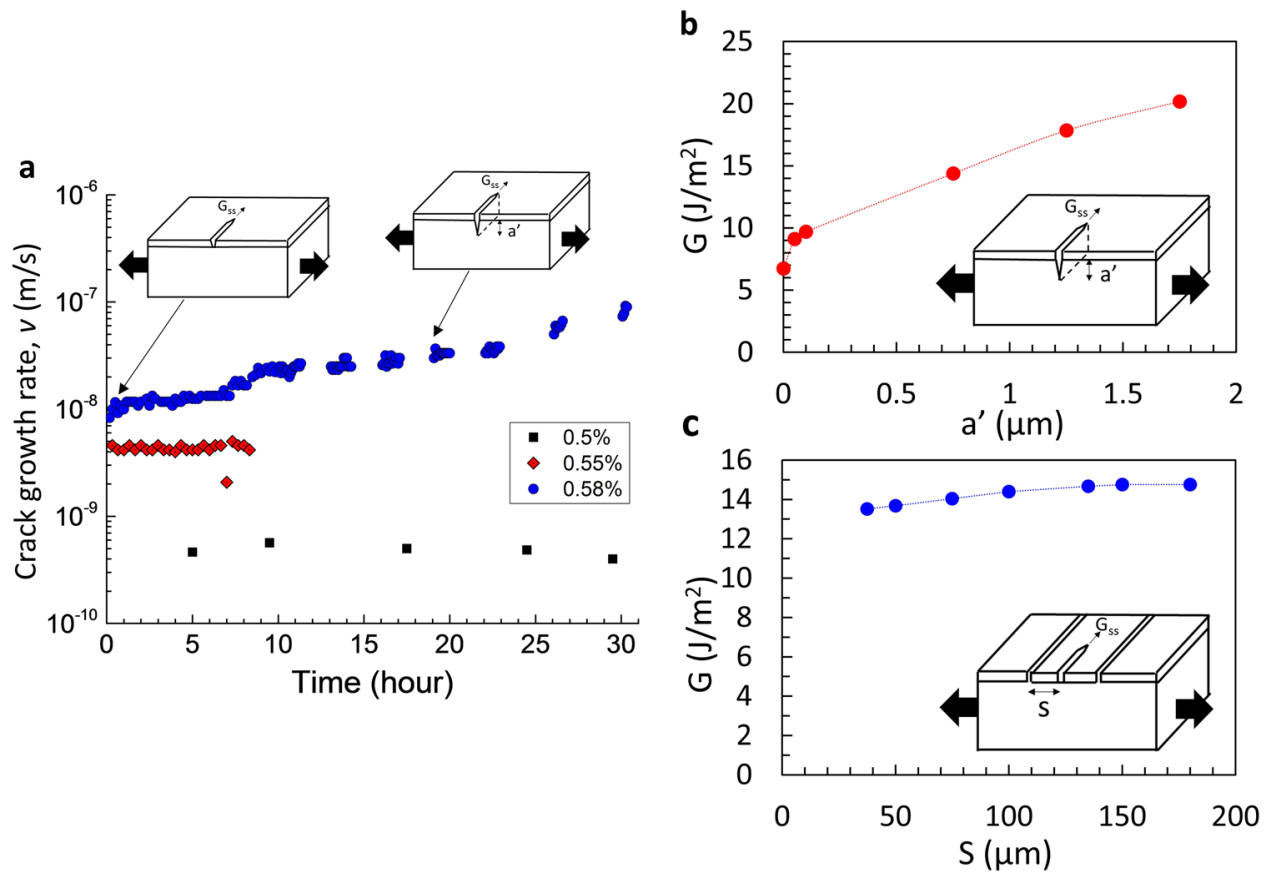

Figure 2. (a) Measured crack growth rate in $\mathrm{SiN}_{\mathrm{x}} / \mathrm{PET}$ at the applied strains of $0.55 \%$ and $0.58 \%$ in air. (b) Calculated driving force of an isolated crack as a function of substrate cracking depth a', when the applied strain is $0.58 \%$. (c) Calculated driving force of a crack with spacing $S$ to the neighboring long crack on its either side, when the applied strain is $0.75 \%$.

cross section images of the $\mathrm{SiN}_{\mathrm{x}} / \mathrm{PET}$ specimen exposed to atmospheric condition for 5 days revealed cracking into the PET substrate directly under the $\mathrm{SiN}_{\mathrm{x}}$ channel crack. The depth of substrate cracking from the interface with $\mathrm{SiN}_{\mathrm{x}}$ coating was about $8 \mu \mathrm{m}$ or 32 times the film thickness. Therefore, the PET substrate undergoes micro-yielding or crazing at the highly stressed channel crack line of the $\mathrm{SiN}_{\mathrm{x}}$ film, which results in substrate cracking evolving with time via the process known as static fatigue or creep rupture ${ }^{32}$. SEM images of a SiN $/$ /PI specimen held for 2 days at $0.75 \%$ reveal very little damage in the substrate, while a $\mathrm{SiN}_{\mathrm{x}} / \mathrm{PET}$ specimen tested under the same conditions reveal again significant substrate cracking. As will be shown in a later section, the crack growth rates for $\mathrm{SiN}_{\mathrm{x}}$ on PI are fairly constant, unlike PET for which significant changes in crack velocities are observed over periods of days. It is therefore likely that the substrate damage is responsible for the observed changes in crack velocities, presumably via changing the driving force for crack extension (which influences crack growth rate based on Fig. 1b). Finite element models were used to quantify the effect of substrate cracking on the driving force for crack extension, $G$, in order to explain the observed crack growth rate behaviors over time. For appropriate crack geometries, channel crack in the film, including various depths of substrate cracking in the growing crack/neighboring cracks, was set up in the model. Then, the $G$ value at the crack tip of the $\mathrm{SiN}_{\mathrm{x}}$ layer was calculated through the J-integral approach. This driving force was used to predict the growth rate using the $v$-G relationship (Fig. 1b).

Single Crack Growth Rate Behavior. First, we studied the change in crack growth rate for isolated or weakly interacting channel cracks with substrate damage. Finite element modeling results show that the change of driving force of crack growth is less than $1 \%$ if the crack spacing is greater than $135 \mu \mathrm{m}$ (Fig. 2c). Further interactions with neighboring cracks on the driving force as a function of crack spacing can be found in the literature $^{33}$. Consequently, we analyzed the behavior of single cracks by ensuring a crack spacing of at least $135 \mu \mathrm{m}$ (Fig. 2a). This condition could only be obtained at low applied strains since the crack density quickly increased at higher strains and introduced strong crack interaction effects. We applied the external-load-assisted channel crack growth technique ${ }^{23}$ to accomplish this. Specifically, cracks were initiated quickly by pulling the sample to a strain of $0.75 \%$, followed by a quick strain reduction in order to prevent large crack densities from forming and to find isolated non-interacting cracks. Based on modeling results (Fig. 2b), the development of substrate cracking in the presence of an isolated or weakly interacting crack is expected to increase the driving force due to loss of mechanical constraint to crack opening displacement and therefore the crack growth rate increases (based on Fig. 1b). Thus, an accelerating isolated crack should give evidence of cracking in the underlying substrate whereas steady state isolated cracking would be an indication of no substrate cracking. For low applied strains of $0.5 \%$ and $0.55 \%$, the growth rates were measured to be constant throughout the long testing periods as shown in Fig. 2a, an indication that no substrate cracking developed. However, at $\varepsilon_{\text {app }}=0.58 \%$, the growth rate increased from 8.3 to $100 \mathrm{~nm} / \mathrm{s}$ over a period of 30 hours (see Fig. 2a), which is an indication of substrate damage. The corresponding increase in crack driving force is estimated to be $33.7 \%$ (from 7.03 to $9.40 \mathrm{~J} / \mathrm{m}^{2}$ ) from its characterized relationship with subcritical crack growth rates (Fig. 1b). Based on Fig. $2 \mathrm{~b}$ (showing modeling results for $\varepsilon_{\text {applied }}=0.58 \%$ ), 

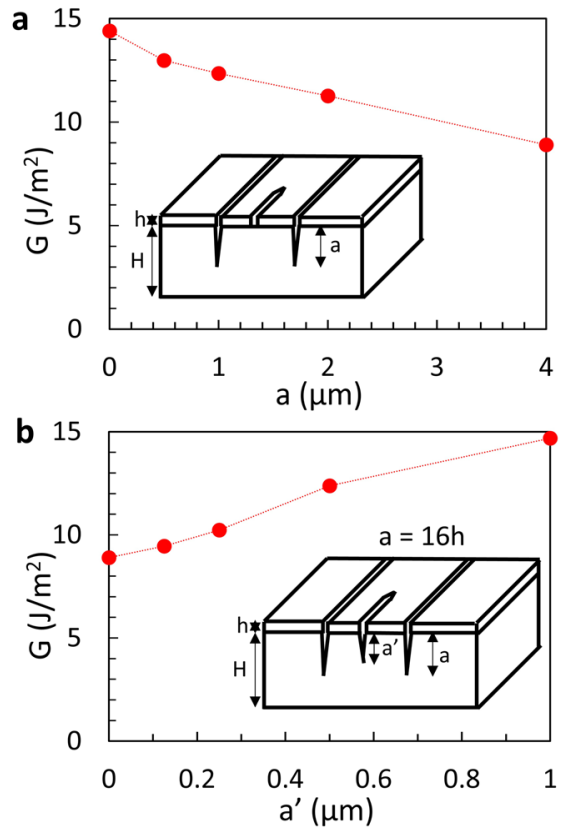
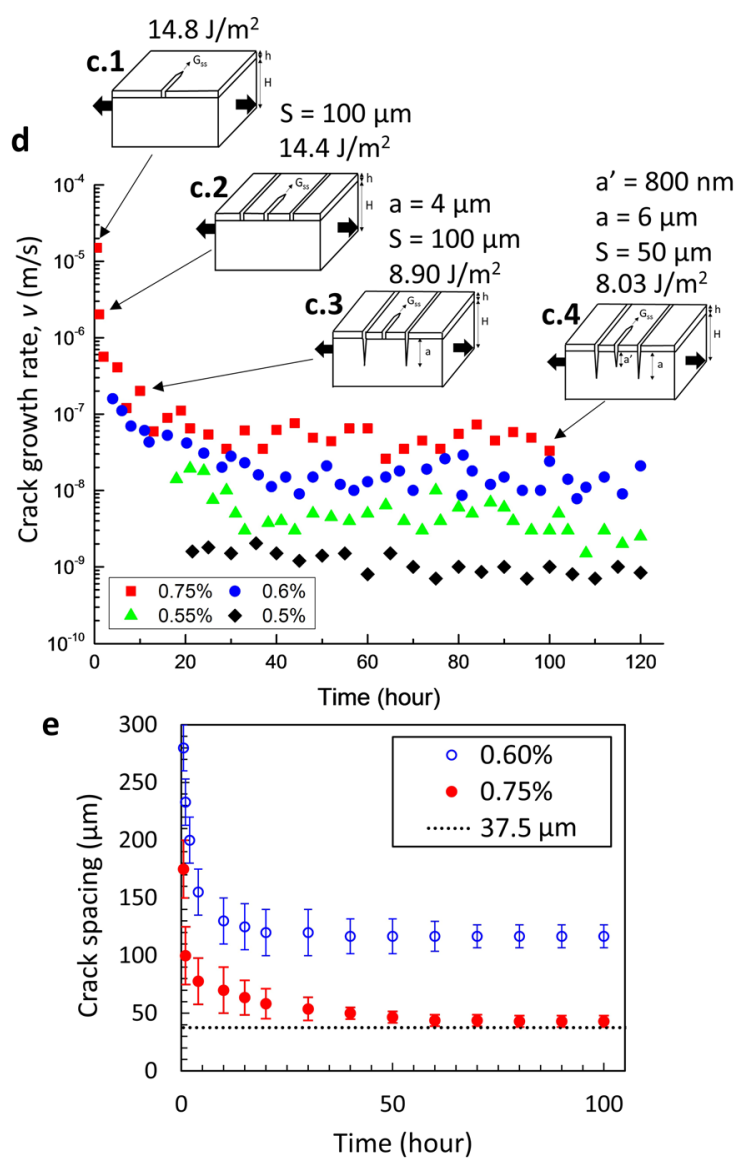

Figure 3. (a) Calculated driving force of a crack as a function of substrate cracking depth of neighboring cracks. (b) Calculated driving force of a crack as a function of substrate cracking depth a' in the presence of neighboring cracks with a fixed substrate cracking depth a. Both (a) and (b) were calculated under the applied strain $0.75 \%$, residual strain $-0.15 \%$, crack spacing $100 \mu \mathrm{m}$. (c) Schematics of different cracking modes in the $\mathrm{SiN}_{\mathrm{x}}$ film and PET substrate, marked with the associated crack driving force, see text for details; crack spacing S, substrate cracking depth in neighboring cracks a and in growing crack a' are chosen for each case. (d) Measured time dependent crack growth rate of $\mathrm{SiN}_{\mathrm{x}} / \mathrm{PET}$ in air, while the applied strain was kept at $0.5,0.55,0.6,0.75 \%$, respectively. For the applied strain $0.6 \%$, the last data point at 120 hours corresponds to the sample in Fig. $1 \mathrm{~d}$. (e) Crack spacing as a function of time at the applied strain of $0.75 \%$ and $0.6 \%$, respectively.

substrate cracking between 50 to $100 \mathrm{~nm}$ would be required to induce that increase in driving force. This amount of substrate damage in 30 hours is reasonable, given that no damage was observed for $0.5 \%$ and $0.55 \%$ strain and that substrate cracking was observed at $0.6 \%$ strain for 5 days (see Fig. 1d.2). The depth of the substrate crack can be more than $50 \sim 100 \mathrm{~nm}$ if the substrate cracking occurs in the neighboring cracks with a spacing over $135 \mu \mathrm{m}$ before it influences the driving force and therefore the crack growth rate. In this case, the crack configuration develops as shown in Fig. 3c.4 (see below, next section).

Multiple Crack Growth Rate Behavior. Figure 3d shows the results of crack growth rate behavior over periods of time greater than $0.5 \mathrm{~h}$ for which substrate damage is expected to play a role. For samples held at strains of $\varepsilon_{\mathrm{app}}=0.75 \%, 0.6 \%, 0.55 \%$ and $0.5 \%$, the initial crack growth rates were $15010 \pm 8560 \mathrm{~nm} / \mathrm{s}, 159 \pm 68 \mathrm{~nm} / \mathrm{s}$, $14.1 \pm 7.5 \mathrm{~nm} / \mathrm{s}$ and $1.6 \pm 0.35 \mathrm{~nm} / \mathrm{s}$, respectively. For the larger rates, the cracks grow and quickly reach the edges of the specimen (width: $5 \mathrm{~mm}$ ), thus the growth rates of different cracks are measured over 100 hours, especially at $0.75 \%$ and $0.6 \%$. These rates decreased over the first $\sim 30-40 \mathrm{~h}$ until they reached steady-state values of $50.0 \pm 13.9 \mathrm{~nm} / \mathrm{s}, 15.5 \pm 5.93 \mathrm{~nm} / \mathrm{s}, 3.74 \pm 1.86 \mathrm{~nm} / \mathrm{s}$ and $1.163 \pm 0.394 \mathrm{~nm} / \mathrm{s}$, respectively. In the case of applied strain of $0.5 \%$, the growth rate is fairly constant. The initial crack growth rates at each applied strain are in the range of the subcritical crack growth rates in $v$-G curve (i.e., crack velocity, $v$, versus the strain energy release rate, $G)$ of $\mathrm{SiN}_{\mathrm{x}}$ thin films as shown in our previous studies, measured for the first half an hour (Fig. 1b) ${ }^{22,23}$. Average crack spacing is plotted as a function of time in Fig. 3e, for tests performed at 0.6 and $0.75 \%$. Along with the evidence of substrate cracking for these extended periods of testing (see Fig. 1d), these data strongly suggest that the observed decreases in crack growth rates are related to increased crack interactions (smaller spacings between cracks for cracks that nucleate and grow in the later stages of the experiments, as more cracks have already propagated through the specimens' width). In addition, substrate damage keeps developing in channel cracks that have already propagated through the specimen's width, hence varying amount of substrate damage can be present in neighboring cracks. 


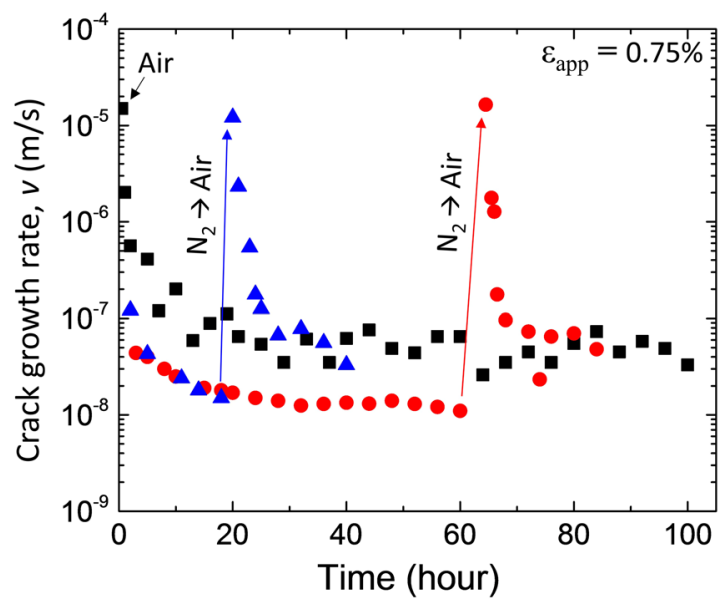

Figure 4. Crack growth rate behavior of $\mathrm{SiN}_{\mathrm{x}} / \mathrm{PET}$ at the applied strain of $0.75 \%$ subjected to change of environmental condition.

Finite element analysis was conducted to provide further insight into the effects of substrate cracking on systems of interacting cracks. For this analysis, a strain of $0.75 \%$ was applied to the model where a single propagating crack is interacting with two adjacent cracks. The spacing of the cracks in the model was chosen to be either 50 or $100 \mu \mathrm{m}$, depending of the observed crack spacings (Fig. 3e). Film and substrate thicknesses were $250 \mathrm{~nm}$ and $125 \mu \mathrm{m}$, respectively. To further explore the parametric space, additional calculations were done on a number of crack configurations (single versus multiple cracks, with and without substrate cracking) to elucidate their impact on crack driving forces (Fig. 3a and b). Results show that substrate cracking in the two adjacent cracks reduces the driving force in the growing crack, as the depth into the substrate increases. The driving force decreases by $40 \%$ with the increase of substrate cracking depth in the neighboring crack up to $4 \mu \mathrm{m}$ (Fig. 3a). This is due to the loss of in mechanical constraint in the neighboring cracks as the substrate crack grows in the PET. This has the equivalent effect of closing the growing crack and reducing the energy available for channel crack growth. Figure $3 \mathrm{~b}$ shows the effect of substrate cracking on the growing crack when the neighboring cracks also induce substrate cracking. When substrate cracking under the growing crack was introduced (up to $1 \mu \mathrm{m}$ in depth), the crack driving force increased up to $65 \%$ while substrate cracking depth in the neighboring cracks was kept at $4 \mu \mathrm{m}$ (Fig. 3b). The increase in driving force with substrate damage under the growing crack is consistent with the results in the previous section as shown in Fig. 2b.

Based on the modeling results (Figs $2 \mathrm{c}$ and $3 \mathrm{a}, \mathrm{b}$ ) and the measured evolution of crack spacing with time (Fig. 3e), a possible scenario for the observed evolution of crack propagation rates can be presented as illustrated in Fig. 3c, with four cases for samples held at $0.75 \%$. The crack driving force value $G$ was extracted from modeling and the corresponding growth rate was calculated from the $v$ - $G$ curve in Fig. $1 \mathrm{~b}$. Initially single channel cracks in $\mathrm{SiN}_{\mathrm{x}}$ develop and the modeling result predicts a driving force of $14.8 \mathrm{~J} / \mathrm{m}^{2}$ (Fig. 3c.1), corresponding to a crack growth rate of $\sim 75 \mu \mathrm{m} / \mathrm{s}$ based on Fig. 1b. The growth rates for the first 30 mins are on the same order of magnitude, i.e. $15 \pm 8.6 \mu \mathrm{m} / \mathrm{s}$ (Fig. $3 \mathrm{~d}$ ). It should be noted that the cracks traverse the full width of the specimen in less than a few minutes, for example, $1 \mathrm{~min}$ for $75 \mu \mathrm{m} / \mathrm{s}$ and $5 \mathrm{mins}$ for $15 \mu \mathrm{m} / \mathrm{s}$, therefore the rates measured after $\sim 0.5 \mathrm{~h}$ are for multiple interacting cracks. So, the second case investigated in the scenario after an hour is channel crack growth with reduced crack spacing as depicted in Fig. 3c.2. By adding two adjacent interacting channel cracks (crack spacing $100 \mu \mathrm{m}$ ), the driving force was reduced to $14.4 \mathrm{~J} / \mathrm{m}^{2}$, corresponding to a slight decrease in crack growth rates $(\sim 50 \mu \mathrm{m} / \mathrm{s}$ based on Fig. $1 \mathrm{~b})$. Up to this part, substrate cracking is not taken into consideration as evident in the SEM image in Fig. 5b (free from the substrate damage in the PET substrate after an hour at strain $0.75 \%)$. However, over time, substrate damage develops first in the existing cracks and the new growing cracks have a lower driving force due to the effect of substrate damage in the neighboring cracks as explained in Fig. 3a, corresponding to the third case in Fig. 3c.3. For example, the crack driving force was further reduced to $8.9 \mathrm{~J} / \mathrm{m}^{2}$ when a $4 \mu \mathrm{m}$ crack was present in the PET under the neighboring cracks (Fig. 3c.3, crack spacing $100 \mu \mathrm{m}$ ). This corresponds to a crack growth rate of $\sim 119 \mathrm{~nm} / \mathrm{s}$ (see Fig. 1b) and is commensurate with the measured rate after 10 hours (see Fig. 3d). At longer times, the cracks were observed to grow much more slowly $(\sim 50-100 \mathrm{~nm} / \mathrm{s})$ and it took more than 20 hours for cracks to traverse the specimen's width. Hence the growing cracks whose rates are measured for more than $30 \mathrm{~h}$ also undergo substrate cracking (Fig. 3c.4). With $800 \mathrm{~nm}$ substrate cracking underneath the growing crack and $6 \mu \mathrm{m}$ neighboring penetration into PET, the driving force is calculated to be $8.03 \mathrm{~J} /$ $\mathrm{m}^{2}$. This last case of the scenario occurs when a steady-state growth rate is observed as shown in Fig. $3 \mathrm{~d}$ after $\sim 30-40 \mathrm{~h}$. This is the result of a balance between additional substrate cracking in the growing crack, i.e. increase of driving force (Fig. 3a) and in the adjacent cracks, i.e. decrease of driving force (Fig. 3b).

Impact of Environmental Conditions on Crack Growth Rate for Interacting Cracks. The effect of environment on the long-term crack growth rate behavior was also studied by performing experiments in dry nitrogen for long periods of time before switching to laboratory air. Figure 4 shows that crack growth rate evolution for a specimen tested in air at $\varepsilon_{\mathrm{app}}=0.75 \%$ along with the evolution for two specimens tested at the same applied strain in dry nitrogen before switching to laboratory air after either $20 \mathrm{~h}$ or $60 \mathrm{~h}$. In dry nitrogen, the initial 
a

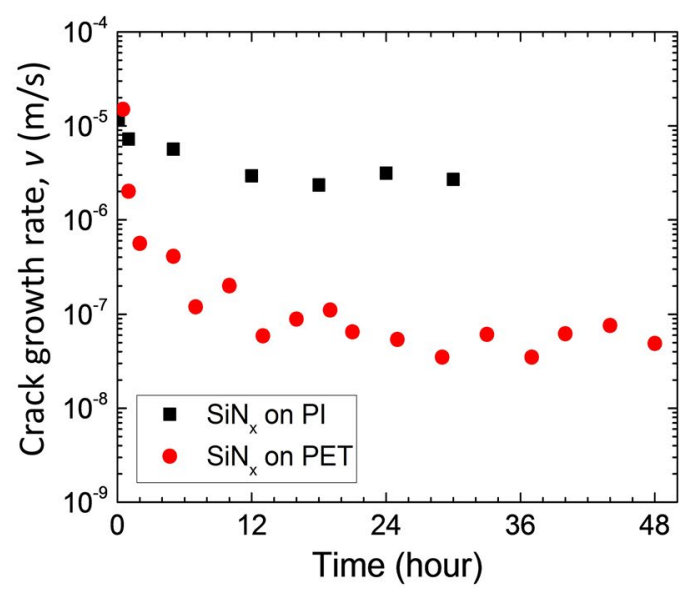

b

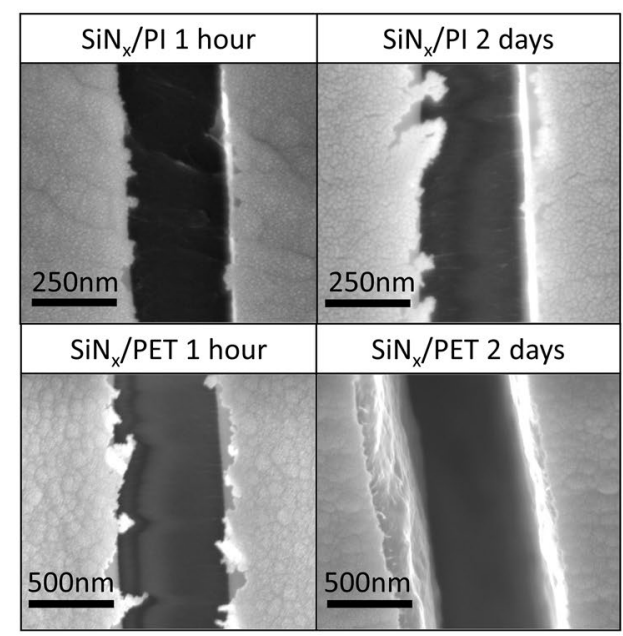

Figure 5. (a) Time-dependent crack growth rate behavior of $\mathrm{SiN}_{\mathrm{x}}$ deposited on $\mathrm{PET}$ at the applied strain $0.75 \%$ versus on PI at the applied strain $0.85 \%$. (b) SEM images of $\mathrm{SiN}_{\mathrm{x}} / \mathrm{PET}$ and $\mathrm{SiN}_{\mathrm{x}} / \mathrm{PI}$ after 1 hour and 2 days passed, respectively.

crack growth rate is two orders of magnitude lower than in the humid environment, which is consistent with Fig. 1b, highlighting environmentally-assisted cracking. A decrease in rate is also observed in dry nitrogen, with a steady-state value reached after $\sim 20 \mathrm{~h}$, but the magnitude of the decrease is much less than in air. This behavior is attributed to the fact that the density of cracks in $\mathrm{N}_{2}$ is two orders of magnitude lower than in air (a few cracks in $\mathrm{N}_{2}$ vs. hundreds of cracks in air) and therefore the effect of the interacting cracks (and their associated substrate damage) is much reduced compared to what was described in the previous section. After switching from $\mathrm{N}_{2}$ to humid air after 20 and $60 \mathrm{~h}$ (for the two specimens shown in Fig. 4), a large increase in the crack growth rate was observed (due to the impact of environmentally-assisted cracking), rising in both cases to rates similar to the initial rates for samples tested in humid air. The newly formed cracks after introducing air behave like a "fresh" specimen tested in air because of the very low density of cracks that formed in nitrogen. The ensuing decrease in crack growth rate is also very similar to that observed in specimens tested in air, suggesting a similar sequence of events described in the previous sections (see Fig. 3c). Lastly, Fig. 4 shows that the steady state rates in nitrogen are only one order of magnitude lower than that in air (while the initial rates were two orders of magnitude lower). The lower relative decrease in nitrogen may be simply due to the lower density of cracks in that environment (leading to lower decreases in driving force), although it is also possible that the humid environment induces more substrate damage that could lead to larger relative decreases in air.

Crack Growth Rate Behavior on PI Substrates. Compared to PET, PI has a higher tensile strength (PI: $340 \mathrm{MPa}$, PET: $170 \mathrm{MPa}$ by ASTM D882) and thus should have greater resistance to substrate damage. Hence, the long-term evolution of crack growth rates in $\mathrm{SiN}_{\mathrm{x}}$ on PI should be markedly different from that measured with PET, under same initial channel crack driving force, $G$. In order to test a $\mathrm{SiN}_{\mathrm{x}}$ specimen on PI with the same initial $G$ value, the $Z$ parameter from Eq. (2) was evaluated for PI. The moduli of elasticity of $\operatorname{SiN}_{\mathrm{x}}$ and polymer substrates were determined by nanoindentation and uniaxial tensile testing, respectivel ${ }^{22,23}$. The modulus of PI was found to be $7.6 \pm 0.17 \mathrm{GPa}$, higher than PET which has found to be $4.07 \pm 0.12 \mathrm{GPa}$. The elastic mismatch between $\operatorname{SiN}_{\mathrm{x}}$ and PI was $\alpha=0.880$ and between $\mathrm{SiN}_{\mathrm{x}}$ and PET was $\alpha=0.934$ and the corresponding dimensionless energy release rates are $Z=8.62$ and $Z=11.8$, respectively ${ }^{34}$. Based on these values, a higher applied strain $0.1 \%$ was required for PI samples, i.e. $0.85 \%$, to match the crack driving forces between PI $\left(13.8 \mathrm{~J} / \mathrm{m}^{2}\right)$ and PET $\left(14.4 \mathrm{~J} / \mathrm{m}^{2}\right.$ for PET at $\left.0.75 \%\right)$. Hence for these two experiments, there is less than $5 \%$ difference in the initial driving force. In calculating $G$ with Eq. (1), the residual strain is also required. For residual compressive strains (as for PECVD $\mathrm{SiN}_{\mathrm{x}}$ films), this can be quantified by first straining (in our case up to $0.8 \%$, subcritical value of crack onset strain) a specimen to form a few channel cracks and then catching the applied strain while unloading at which the cracks start closing and become invisible ${ }^{22}$. Residual strains were found to be $-0.15 \%$ for both PI and PET. As shown in Fig. 5a, the decrease in crack growth rate with time for $\mathrm{SiN}_{\mathrm{x}} / \mathrm{PI}$ was much less than that of $\mathrm{SiN}_{\mathrm{x}} /$ PET. In SEM images, substrate cracking was not detected in both of PI and PET after one hour. However, after 2 days, crack penetration was observed in the PET as expected, whereas PI was still free from substrate cracking. A little decrease in crack growth rate of $\mathrm{SiN}_{\mathrm{x}} / \mathrm{PI}$ presumably came from inherent damage on the top surface of the substrate. It is important to note that, when both of the substrates are under the same value of applied strain, the number of cracks in $\mathrm{SiN}_{\mathrm{x}} / \mathrm{PI}$ was greatly decreased when compared to $\mathrm{SiN}_{\mathrm{x}} / \mathrm{PET}$. For example, at the center of the specimen after 2 days of testing, $255 \pm 32$ cracks were accumulated in $\mathrm{SiN}_{\mathrm{x}} / \mathrm{PET}$ while $21 \pm 5$ cracks were accumulated in $\mathrm{SiN}_{\mathrm{x}} / \mathrm{PI}$. This certainly demonstrates that depositing barriers on substrates with high tensile strength and therefore resistance to substrate damage is one effective means of improving the reliability of barrier films under long-term mechanical loading. 


\begin{tabular}{|c|c|c|c|c|c|}
\hline $\begin{array}{l}\text { Mechanical } \\
\text { properties (units) }\end{array}$ & $\begin{array}{l}\text { PECVD SiN } \\
\text { film }\end{array}$ & $\begin{array}{l}\text { Mechanical } \\
\text { properties (units) }\end{array}$ & PET substrate & $\begin{array}{l}\text { Mechanical } \\
\text { properties (units) }\end{array}$ & PI substrate \\
\hline$E_{f}(\mathrm{GPa})$ & $123 \pm 5.8$ & $E_{\mathrm{s}}^{*}(\mathrm{GPa})$ & $4.47 \pm 0.25$ & \multirow{5}{*}{$E_{\mathrm{s}}^{*}(\mathrm{GPa})$} & \multirow{5}{*}{$8.35 \pm 0.19$} \\
\hline$v_{\mathrm{f}}$ & 0.253 & $\sigma_{0}(\mathrm{MPa})$ & 90.6 & & \\
\hline$E_{f}^{*}(\mathrm{GPa})$ & $131 \pm 6.2$ & $D\left(\mathrm{hr}^{-1}\right)$ & 80 & & \\
\hline \multirow[t]{2}{*}{$\varepsilon_{r e s}(\%)$} & $-0.15 \pm 0.02$ & $n^{\prime}$ & 20 & & \\
\hline & & $\sigma_{\mathrm{y}}(\mathrm{MPa})$ & $50 \times\left(1+1.74 \varepsilon_{p}\right)$ & & \\
\hline
\end{tabular}

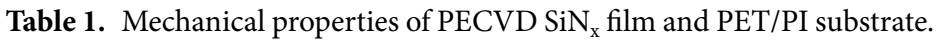

\section{Methods}

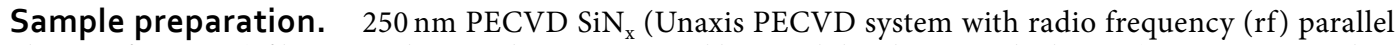
plate configuration) films were deposited on commercial heat-stabilized $125 \mu \mathrm{m}$ thick PET (Dupont Teijin Films Melinex ST505) and on PI (UPILEX-125S) at a temperature of $110^{\circ} \mathrm{C}$, pressure of 1 Torr, $20 \mathrm{~W}$ rf plasma and a rate of $10 \mathrm{~nm} / \mathrm{min}$. The substrates were laser cut prior to deposition to a size of $5 \mathrm{~mm}$ by $50 \mathrm{~mm}$ to prevent damage that can occur in trying to cut out samples post deposition.

Microscopy and image analysis. In-situ microscopy from an optical microscope (Edmund Optics, 1312 M 59-365) was used to observe the time-dependent crack propagation on the surface of PECVD $\operatorname{SiN}_{\mathrm{x}}$ film deposited on laser-cut $50 \mathrm{~mm}$ long and $5 \mathrm{~mm}$ wide samples using a microtensile testing stage (Linkam Scientific Instruments, TST350). Detailed experimental information is explained in our previous work ${ }^{22,23}$. To observe the substrate cracking, samples were stretched up to a maximum 5 days, i.e. 120 hours, so that a sufficiently large crack could be observed. Tests were performed in a controlled environment as well as laboratory air. Specifically, the environmental condition was switched from dry nitrogen (i.e., $2 \mathrm{ppm}$ ) to air (i.e., relative humidity content of $30 \%$ ) after $20 \mathrm{~h}$ and $60 \mathrm{~h}$ passed to show the impact of environmentally assisted cracking while the substrate cracking in long term crack growth behavior. For switching to air from dry nitrogen, the lid was removed from the stage and the nitrogen gas pumping was stopped at the same time therefore the sample was immediately exposed to air. The crack growth rates were measured after the required crack spacing was confirmed to involve or eliminate the interaction from neighboring cracks while optical imaging tracked through the observation area (region with a radius of $13.6 \mathrm{~mm}$ ). To isolate the crack growth not to interact with neighboring cracks, $0.58 \%$ strain was required not to increase the density of cracks. The external-load-assisted channel crack growth technique was applied to achieve this condition without difficulty ${ }^{23}$. The density of cracks was also calculated by counting the number of propagated cracks in the observation area. Additionally, the crack configuration was specified from scanning electron microscope (SEM) images (Hitachi SU8230) and some of the specimens were further investigated by creating samples for imaging using a focused ion beam (FIB) (Nova FIB Micromanipulator, $30 \mathrm{kV}$ $1-3 \mathrm{nA}$ for FIB and $5 \mathrm{kV} 0.4 \mathrm{nA}$ for SEM) on where the channel crack is located. Au/Pd was sputtered (10 nm) on tested specimen before FIB to reduce charging effects. A 30 by $30 \mu \mathrm{m}^{2}$ area was etched up to $10 \mu \mathrm{m}$ deep.

Mechanical characterization of $\mathrm{SiN}_{\mathrm{x}}$ film, poly (ethylene terephthalate) substrate and polyimide substrate. Several mechanical properties are required to quantify the driving force for channel crack propagation. As mentioned previously, nanoindentation (Hysitron triboindenter) was used to measure the modulus of the $\operatorname{SiN}_{\mathrm{x}}$ film $E_{f}$. A $1 \mu \mathrm{m}$ thick PECVD $\mathrm{SiN}_{\mathrm{x}}$ on a $\mathrm{Si}$ substrate was indented to a depth of $100-300 \mathrm{~nm}$. The microtensile stage was used to obtain uniaxial tensile properties of the PET and PI substrates. Table 1 summarizes all the related mechanical properties mentioned above.

Numerical model. PET was modeled as an elastic-viscoplastic material, while $\mathrm{SiN}_{\mathrm{x}}$ a purely elastic material. For PET, the elastic strain rate $\dot{\varepsilon}_{\mathrm{e}}$ is linearly proportional to the stress rate $\dot{\sigma}$ as

$$
\dot{\varepsilon}_{\mathrm{e}}=\dot{\sigma} / E_{\mathrm{s}}
$$

where $E_{s}$ is the elastic modulus; a Cowper-Symonds overstress power law was applied to calculate the plastic strain rate.

$$
\dot{\varepsilon}_{p}=D\left(\frac{\sigma}{\sigma_{Y}\left(\varepsilon_{p}\right)}-1\right)^{n^{\prime}}
$$

where $D$ and $n^{\prime}$ are the material constants, $\sigma_{\mathrm{Y}}\left(\varepsilon_{\mathrm{p}}\right)$ is the yield stress that depends on the total yield strain $\varepsilon_{\mathrm{p}}$. These material properties are summarized in Table 1. Since no debonding was observed during experiments under subcritical loading, perfect bonding was assumed between the $\mathrm{SiN}_{\mathrm{x}}$ thin film and PET substrate. Due to the large elastic mismatch between $\mathrm{SiN}_{\mathrm{x}}$ thin film and PET substrate, large stress gradients may develop in PET parts underneath the cracks. To capture such large stress gradients in the PET substrate, a dense mesh scheme was employed for PET underneath the cracks. The growing crack in the PET substrate was modeled as an opening wedge. Penetration depth of the crack in the PET substrate can markedly affect the driving force of crack extension in the $\mathrm{SiN}_{\mathrm{x}}$ thin film, due to a loss of substrate constraints. In our previous work ${ }^{22}$, we showed that the driving force change originating from the viscous response of polymer substrate is negligible. Specifically, PET relaxation at $0.95 \%$ applied strain resulted in less than $1 \%$ of $G$ value change over 30 min and this amount 
of change will decrease and become negligible as the relaxation goes to a steady-state value over time. Therefore, the elastic-viscoplastic substrate behaves like an elastic substrate and each $G$ value at different depths of substrate cracking does not involve the viscous substrate effect at the subcritical value of applied strain. All the numerical simulations were performed using ABAQUS 6.13 $3^{35}$.

\section{References}

1. Zhang, S., Xue, W. \& Yu, Z. Moisture barrier evaluation of SiOx/SiNx stacks on polyimide substrates using electrical calcium test. Thin Solid Films 580, 101-105, https://doi.org/10.1016/j.tsf.2015.02.023 (2015).

2. van Assche, F. J. H. et al. On the intrinsic moisture permeation rate of remote microwave plasma-deposited silicon nitride layers. Thin Solid Films 558, 54-61, https://doi.org/10.1016/j.tsf.2014.02.069 (2014).

3. Majee, S., Geffroy, B., Bonnassieux, Y. \& Bourée, J.-E. Interface effects on the moisture barrier properties of SiNx/PMMA/SiNx hybrid structure. Surface and Coatings Technology 254, 429-432, https://doi.org/10.1016/j.surfcoat.2014.06.059 (2014).

4. Rochat, G. \& Fayet, P. Characterization of Mechanical Properties of Ultra-thin Oxide Coatings on Polymers by Uniaxial Fragmentation Tests. Journal of Adhesion Science and Technology 26, 2381-2392, https://doi.org/10.1163/156856111x599517 (2012).

5. Andringa, A. M. et al. Low-Temperature Plasma-Assisted Atomic Layer Deposition of Silicon Nitride Moisture Permeation Barrier Layers. ACS applied materials \& interfaces 7, 22525-22532, https://doi.org/10.1021/acsami.5b06801 (2015).

6. Bulusu, A. et al. Engineering the mechanical properties of ultrabarrier films grown by atomic layer deposition for the encapsulation of printed electronics. Journal of Applied Physics 118, 085501, https://doi.org/10.1063/1.4928855 (2015).

7. Li, F. M. et al. 18.3: Flexible Barrier Technology for Enabling Rollable AMOLED Displays and Upscaling Flexible OLED Lighting. SID Int. Symp. Dig. Tech. Pap. 44 (2013).

8. Ok, K.-H. et al. Ultra-thin and smooth transparent electrode for flexible and leakage-free organic light-emitting diodes. 5, 9464 , https://doi.org/10.1038/srep09464 (2015).

9. Bae, M. S., Park, C., Shin, D., Lee, S. M. \& Yun, I. Effects of mechanical stresses on the reliability of low-temperature polycrystalline silicon thin film transistors for foldable displays. Solid-State Electronics 133, 1-5 (2017).

10. Choi, G.-M. et al. Flexible Hard Coating: Glass-Like Wear Resistant, Yet Plastic-Like Compliant, Transparent Protective Coating for Foldable Displays. Adv Mater 29, https://doi.org/10.1002/adma.201700205 (2017).

11. Kim, I. et al. Selective Light-Induced Patterning of Carbon Nanotube/Silver Nanoparticle Composite to Produce Extremely Flexible Conductive Electrodes. ACS Applied Materials and Interfaces 9, 6163-6170, https://doi.org/10.1021/acsami.6b14580 (2017).

12. Lee, M.-T. et al. Achieving a foldable and durable OLED display with BT.2020 color space using innovative color filter structure. https://doi.org/10.1002/jsid.533 (2017).

13. Lee, S. M., Shin, D. \& Yun, I. Degradation mechanisms of amorphous ingazno thin-film transistors used in foldable displays by dynamic mechanical stress. IEEE Transactions on Electron Devices 64, 170-175, https://doi.org/10.1109/TED.2016.2631597 (2017).

14. Yoon, J. et al. Superflexible, high-efficiency perovskite solar cells utilizing graphene electrodes: Towards future foldable power sources. Energy and Environmental Science 10, 337-345, https://doi.org/10.1039/c6ee02650h (2017).

15. Baumert, E. K. \& Pierron, O. N. Fatigue properties of atomic-layer-deposited alumina ultra-barriers and their implications for the reliability of flexible organic electronics. Appl. Phys. Let. 101, 251901-251905 (2012).

16. Sadeghi-Tohidi, F., Samet, D., Graham, S. \& Pierron, O. Comparison of the cohesive and delamination fatigue properties of atomiclayer-deposited alumina and titania ultrathin protective coatings deposited at $200 \hat{\mathrm{A}} \hat{\mathrm{A}}^{\circ} \mathrm{C}$. Sci. Technol. Adv. Mater. 15, 015003 (2014).

17. Jen, S.-H., Bertrand, J. A. \& George, S. M. Critical tensile and compressive strains for cracking of Al2O3 films grown by atomic layer deposition. Journal of Applied Physics 109, 084305, https://doi.org/10.1063/1.3567912 (2011).

18. Jen, S.-H., Lee, B. H., George, S. M., McLean, R. S. \& Carcia, P. F. Critical tensile strain and water vapor transmission rate for nanolaminate films grown using $\mathrm{Al} 2 \mathrm{O} 3$ atomic layer deposition and alucone molecular layer deposition. Applied Physics Letters 101, 234103, https://doi.org/10.1063/1.4766731 (2012).

19. Miller, D. C. et al. The mechanical robustness of atomic-layer- and molecular-layer-deposited coatings on polymer substrates. Journal of Applied Physics 105, 093527, https://doi.org/10.1063/1.3124642 (2009).

20. Andersons, J. et al. Evaluation of toughness by finite fracture mechanics from crack onset strain of brittle coatings on polymers. Theoretical and Applied Fracture Mechanics 49, 151-157, https://doi.org/10.1016/j.tafmec.2007.11.002 (2008)

21. Leterrier, Y. Durability of Nanosized Oxygen-barrier Coatings on Polymers. Prog. Mater. Sci. 48, 1-55 (2003).

22. Kim, K. et al. Environmentally Assisted Cracking in Silicon Nitride Barrier Films on Poly(ethylene terephthalate) Substrates. ACS applied materials \& interfaces, https://doi.org/10.1021/acsami.6b06417 (2016).

23. Kim, K., Graham, S. \& Pierron, O. N. Note: A single specimen channel crack growth technique applied to brittle thin films on polymer substrates. Rev Sci Instrum 88, 036102, https://doi.org/10.1063/1.4977473 (2017).

24. Hutchinson, J. W. \& Suo, Z. Mixed mode cracking in layered materials. Advances in applied mechanics 29, 191 (1992).

25. Beuth, J. Cracking of thin bonded films in residual tension. International Journal of Solids and Structures 29, 1657-1675 (1992).

26. Dundurs, J. Discussion: "Edge-bonded dissimilar orthogonal elastic wedges under normal and shear loading” (Bogy, DB, 1968, ASME J. Appl. Mech., 35, pp. 460-466). Journal of applied mechanics 36, 650-652 (1969).

27. Thouless, M. D., Li, Z., Douville, N. J. \& Takayama, S. Periodic cracking of films supported on compliant substrates. Journal of the mechanics and physics of solids 59, 1927-1937, https://doi.org/10.1016/j.jmps.2011.04.009 (2011).

28. Douville, N. J., Li, Z., Takayama, S. \& Thouless, M. D. Fracture of metal coated elastomers. Soft Matter 7, 6493, https://doi. org/10.1039/clsm05140g (2011).

29. Thouless, M. Crack spacing in brittle films on elastic substrates. Journal of the American Ceramic Society 73, 2144-2146 (1990).

30. Delannay, F. \& Warren, P. On crack interaction and crack density in strain-induced cracking of brittle films on ductile substrates. Acta metallurgica et materialia 39, 1061-1072 (1991).

31. Kang, D. et al. Ultrasensitive mechanical crack-based sensor inspired by the spider sensory system. Nature 516, 222-226 (2014)

32. Wright, D. C. Environmental stress cracking of plastics. (iSmithers Rapra Publishing, 1996).

33. Xia, Z. C. \& Hutchinson, J. W. Crack patterns in thin films. Journal of the mechanics and physics of solids 48, 1107-1131 (2000).

34. Huang, R., Prévost, J. H., Huang, Z. Y. \& Suo, Z. Channel-cracking of thin films with the extended finite element method. Engineering Fracture Mechanics 70, 2513-2526, https://doi.org/10.1016/s0013-7944(03)00083-3 (2003).

35. ABAQUS/Standard 6.13, User's Manual, SIMULIA, Providence, RI. (2010).

\section{Acknowledgements}

The authors acknowledge financial support from NSF CMMI through award 1400077.

\section{Author Contributions}

S.G. and O.P. conceived the project and guided the understanding of the mechanical issues. K.K. fabricated samples, performed experiments and analyzed data. H.L. and T.Z. performed simulations and analyzed data. All authors were involved in the writing and review of the manuscript. 


\section{Additional Information}

Competing Interests: The authors declare no competing interests.

Publisher's note: Springer Nature remains neutral with regard to jurisdictional claims in published maps and institutional affiliations.

(c) (i) Open Access This article is licensed under a Creative Commons Attribution 4.0 International License, which permits use, sharing, adaptation, distribution and reproduction in any medium or format, as long as you give appropriate credit to the original author(s) and the source, provide a link to the Creative Commons license, and indicate if changes were made. The images or other third party material in this article are included in the article's Creative Commons license, unless indicated otherwise in a credit line to the material. If material is not included in the article's Creative Commons license and your intended use is not permitted by statutory regulation or exceeds the permitted use, you will need to obtain permission directly from the copyright holder. To view a copy of this license, visit http://creativecommons.org/licenses/by/4.0/.

(c) The Author(s) 2018 